\title{
Diet quality in European pre-schoolers: evaluation based on diet quality indices and association with gender, socio-economic status and overweight, the ToyBox-study
}

\author{
An-Sofie Pinket ${ }^{1, *}$, Marieke De Craemer ${ }^{2}$, Inge Huybrechts ${ }^{3}$, Ilse De Bourdeaudhuij ${ }^{2}$, \\ Benedicte Deforche ${ }^{1,4}$, Greet Cardon ${ }^{2}$, Odysseas Androutsos 5 , Berthold Koletzko6, \\ Luis Moreno ${ }^{7}$, Piotr Socha ${ }^{8}$, Violeta lotova ${ }^{9}$, Yannis Manios ${ }^{5}$ and Wendy Van Lippevelde ${ }^{1}$, \\ on behalf of the ToyBox-study group \\ 'Department of Public Health, Ghent University, Unit Health Promotion, De Pintelaan 185 - 4K3 lokaal 036, 9000 \\ Gent, Belgium: ${ }^{2}$ Department of Movement and Sport Sciences, Ghent University, Ghent, Belgium: ${ }^{3}$ Dietary Exposure \\ Assessment Group (DEX), International Agency for Research on Cancer (IARC/WHO), Lyon, France: ${ }^{4}$ Department \\ of Human Biometry and Biomechanics, Vrije Universiteit Brussel, Brussels, Belgium: ${ }^{5}$ Department of Nutrition and \\ Dietetics, School of Health Science and Education, Harokopio University, Athens, Greece: 'Dr von Hauner Children's \\ Hospital, Ludwig-Maximilians-University of Munich, Munich, Germany: ${ }^{7}$ GENUD (Growth, Exercise, NUtrition and \\ Development) Research Group, University of Zaragoza, Zaragoza, Spain: ${ }^{8}$ The Children's Memorial Health Institute, \\ Warsaw, Poland: ${ }^{9}$ Department of Pediatrics and Medical Genetics, Medical University of Varna, Varna, Bulgaria
}

Submitted 25 September 2015: Final revision received 19 January 2016: Accepted 29 February 2016: First published online 18 April 2016

\begin{abstract}
Objective: To study diet quality among pre-schoolers using the Diet Quality Index (DQI) and to investigate differences according to gender, socio-economic status (SES) and overweight/obesity status.

Design: Kindergarten-based cross-sectional survey within the ToyBox-study. A standardized protocol was used and parents/caregivers self-reported sociodemographic data and a semi-quantitative FFQ. A total DQI and its four subcomponents (diversity, quality, equilibrium and meal index) were calculated based on this FFQ. High total DQI scores indicate better diet quality than low scores. Results of the total DQI and the subcomponents were reported as percentages of maximum scores (100\%).

Setting: Kindergartens in six European countries (Belgium, Bulgaria, Germany, Greece, Poland and Spain).

Subjects: European pre-schoolers (aged $3 \cdot 5-5 \cdot 5$ years) and their parents/caregivers ( $n$ 7063).

Results: The mean total DQI score was $68.3 \%$. Mean scores of the subcomponents were $61.7 \%$ for diversity, $56.5 \%$ for quality, $65.4 \%$ for equilibrium and $89.7 \%$ for the meal index. Pre-schoolers of lower-SES backgrounds had lower scores on the total DQI and all its subcomponents. No clear differences were found by gender and overweight status. Results differed slightly according to country.

Conclusions: Pre-schoolers scored low on the total DQI and especially on dietary quality, as energy-dense, low-nutritious food items were more often consumed than highly nutritious food items. Furthermore, already in pre-schoolers lower-SES mothers were less likely to provide a good diet quality and this was consistent for all four subcomponents of the total DQI. Food intake in pre-schoolers should be enhanced, especially in pre-schoolers of lower-SES backgrounds.
\end{abstract}

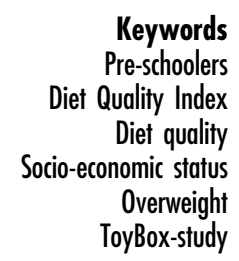

Keywords Quality Index quality

ToyBox-study
The importance of a healthy diet already starts early in life because dietary habits are being formed at a young age and track into adolescence and adulthood ${ }^{(1,2)}$. However, the diet of European (pre-school) children is found to be poor as many children do not reach the dietary guidelines ${ }^{(3-6)}$. Nevertheless, comparison between countries and different studies is difficult because of the variety of measurement methods used to asses dietary status in pre-schoolers. Huybrechts and colleagues developed and validated a Diet Quality Index (DQI) for pre-schoolers 
which enables the identification of diet quality across young children in different countries based on an $\mathrm{FFQ}^{(7)}$.

The DQI consists of four index components: dietary diversity, dietary quality, dietary equilibrium and the meal index ${ }^{(7)}$. The first component, dietary diversity, stresses the importance of food intake variety to reduce morbidity and mortality ${ }^{(7,8)}$. To meet macro- and micronutrient needs, eating a variety of foods is essential ${ }^{(9,10)}$. However, a maximum diversity score does not necessarily imply an optimal quality of food choice within the food groups. Hence, the second component is the dietary quality score. Highly nutritious food items (such as fresh fruit) should be recommended and energy-dense, low-nutritious food items (such as sweet snacks) should be discouraged ${ }^{(7,8,11)}$. The dietary equilibrium score, the third component of total dietary quality, is composed of two subcomponents: adequacy and excess/moderation ${ }^{(7,8)}$. An adequate but moderate intake of each food group is recommended to maintain a healthy diet ${ }^{(8)}$. The daily intake should reach the minimum recommendation to cover the needs of all nutrients, which is investigated in the adequacy score. However, the daily intake should not exceed the maximum recommendation. Hence, this is investigated in the excess score ${ }^{(7,8)}$. Portion sizes should be adapted to the age of the child ${ }^{(11)}$. Barlow and an expert committee selected the limiting of portion sizes, adapted to the age of the child, as a target behaviour to prevent excessive weight gain ${ }^{(12)}$. The last component of dietary quality is the meal index. A certain number of meals per day is recommended in a healthy diet ${ }^{(13)}$. The total DQI is calculated from the sum of the four index subcomponents. High total DQI scores indicate a better diet quality of the pre-schoolers than low scores ${ }^{(7,8)}$. By using four different subcomponents to determine total diet quality, the complex and multidimensional nature of eating patterns is covered. This complex nature of eating patterns is missing in studies focusing on one or more specific food items ${ }^{(14)}$.

Studies that investigate the multidimensional nature of eating patterns in pre-schoolers are scarce. Current studies often have a narrow focus on one or more food items or are regional ${ }^{(3-7)}$. A Flemish study using the DQI for preschoolers of Huybrechts et al. found rather low scores on diet quality in pre-schoolers ${ }^{(7)}$. A Greek study reported a poor diet in pre-schoolers based on the Healthy Eating Index (HEI), a diet quality index based on food and nutrient guidelines ${ }^{(4)}$. A cross-European study on the diet quality of pre-schoolers is currently lacking.

Additionally, few studies have examined the relationship between diet quality and gender, socio-economic status (SES) and overweight. However, insight into differences by gender, SES and weight status may be important to target subgroups in interventions. A Greek study on diet quality in pre-schoolers based on the HEI reported a better overall diet quality and a better variety in boys compared with girls, while other studies found no differences according to gender ${ }^{(1,4)}$. To the best of our knowledge, no previous studies have investigated the relationship between overall diet quality and SES in European pre-schoolers. However, several studies have investigated the relationship between specific food and nutrient intakes and SES in children ${ }^{(15)}$. These studies showed that children of lower-SES backgrounds consumed more fat, sweets and soft drinks, and less fruit and vegetables, than children of high-SES backgrounds ${ }^{(15-17)}$. A difference in diet quality by SES could be expected, with high-SES pre-schoolers having better scores than their lower-SES peers. Also, little is still known about the relationship between overweight and diet quality in preschoolers. Unhealthy food choices can lead to overweight or obesity, so a difference in diet quality could be expected according to weight status, with pre-school children with overweight or obesity having lower scores than pre-schoolers with a normal weight ${ }^{(5,12,18,19)}$. In addition, an interaction between gender, SES and overweight can be expected.

The purpose of the present study was to: (i) examine the diet quality of European pre-schoolers, based on the DQI scores; (ii) investigate the differences in diet quality according to gender, SES (educational level of the mother) and overweight/obesity status; and (iii) investigate the interaction between gender, SES and overweight on diet quality. Data were collected in the context of the ToyBoxstudy (multifactorial evidence-based approach using behavioural models in understanding and promoting fun, healthy food, play and policy for the prevention of obesity in early childhood) in six European countries. Diet quality and differences in diet quality were investigated in the total sample and in all six countries. By using one DQI, comparison between the European countries is possible. A cross-European study may be more valuable than a study with a regional focus.

\section{Methods}

\section{Study background}

Detailed sampling methods have been described elsewhere $^{(20)}$. The ToyBox-study is an EU-funded largescale study of pre-schoolers (3.5-5.5 years old) and their families from six European countries (Belgium, Bulgaria, Germany, Greece, Poland and Spain). It aimed to develop and evaluate a kindergarten-based, family-involved intervention to prevent overweight and obesity in pre-school children (www.toybox-study.eu) ${ }^{(21)}$. For the present study, the cross-sectional baseline data from the ToyBoxstudy were used.

The ToyBox-study was approved by ethical committees and local authorities in all six European countries, in line with national regulations (i.e. Ethical Committee of Ghent University Hospital (Belgium); Committee for the Ethics of the Scientific Studies (KENI) at the Medical University of Varna (Bulgaria); Ethikkommission der 
Ludwig-Maximilians-Universität München (Germany); Ethics Committee of Harokopio University of Athens and Ministry of Education (Greece); Ethical Committee of Children's Memorial Health Institute (Poland); and CEICA (Comité Ético de Investigación Clínica de Aragón; Spain)). Parents/caregivers were asked for written informed consent for the participation of their child and themselves in the study.

\section{Participants}

The pre-school children and their families were recruited at kindergartens, day-care centres or pre-school settings, depending on the country regulations and legislation. Precisely, in Germany, Bulgaria, Spain and Poland children/families were recruited from kindergartens, in Greece from kindergartens and day-care centres, and in Belgium from pre-school settings. In order to avoid confusion for the reader, all these settings (kindergartens, day-care centres, pre-school settings) are referred to as 'kindergartens' herein. Kindergartens were recruited from different sociodemographic backgrounds within each of the provinces (West and East Flanders in Belgium, Varna in Bulgaria, Bavaria in Germany, Attica in Greece, Warsaw and surroundings in Poland, Zaragoza in Spain). Lists of all municipalities that exist within the selected provinces were created with information on the SES variables of the municipalities (mean years of education of the population aged $25-55$ years or mean annual household income). Tertiles including three different sociodemographic groups were created based on the selected SES variables and each country randomly selected approximately five municipalities per SES status: five municipalities for low SES, five for medium SES and five for high SES. Then, kindergartens within these randomly chosen municipalities were randomly selected (with the exclusion of the lowest $20 \%$ of the kindergartens with the smallest number of pupils). The number of kindergartens varied in each municipality, depending on reaching the minimum sample of 1100 pre-schoolers per country. All children whose parents gave written consent were included in the baseline measurements and questionnaires. This means that the number of children in each kindergarten differed by number of registered children and number of informed consents.

A minimum sample of 800 children and their families and twenty kindergartens per country, resulting in a total sample of 4800 children and their families and 120 kindergartens, was initially targeted. However, in order to account for an estimated dropout rate of about $30 \%$, a minimum total number of about 6500 children and their families were aimed to be recruited in the six participating countries. Therefore, a minimum sample of 1100 preschoolers per country was targeted. These numbers are based on detailed power calculations described elsewhere $^{(20)}$. Data collection occurred between May and June 2012.

\section{Measures}

\section{Food and beverage intakes}

Parents/caregivers were asked to describe the child's usual food and beverage habits over the last 12 months in a self-administered FFQ for pre-school children, which was developed based on a previously validated FFQ developed by Huybrechts et al. ${ }^{(22)}$. For each of the thirty-seven food and beverage items, the frequency of consumption was asked. Response categories were: 'never or less than once per month', '1-3 days per month', '1 day per week', '2-4 days per week', '5-6 days per week' and 'every day'. Next, the average consumption per day was asked. Parents/caregivers were asked to indicate the portion size category that best fitted the daily portion of their child. The response categories varied depending on the food item and a list of common standard measures as examples was given, as well as colour images to facilitate the selection of portion sizes. Dietary data from the FFQ were converted to average daily intake values by multiplication of number of days per week and amount per day then dividing by $7^{(22)}$.

To avoid missing scores, the following encodings, based on encoding of Huybrechts et al. ${ }^{(22)}$, in the FFQ data were made. When no score was given for portion size and the frequency was scored ' 1 ' (never or less than once per week), it was considered that the children did (almost) never consume the item and the portion size was scored ' 0 '. When the score on portion size was missing but the frequency was not missing and not ' 1 ', the median of the portion size of that item was given as the score on this item. Children with a missing score both on frequency and portion size on an item of the FFQ were considered as non-consumers and their score was changed into ' 0 ', both on frequency and portion size of that item. When a score on frequency was missing but a portion size was mentioned, the score on frequency was replaced by the median of the frequency of that item.

Pre-school children who had no data on both frequency and portion size for all thirty-seven items were excluded from the study $(n 74)$.

\section{Diet Quality Index}

The DQI for pre-school children was developed based on the Flemish active food triangle and assesses the compliance of pre-schoolers with the Flemish food-based dietary guidelines ${ }^{(8,23)}$. The triangle recommends a daily intake for each food group (non-sugared beverages; bread, cereals, potatoes and grains; vegetables; fruit; milk products and calcium-enriched soya products; meat, fish, eggs and meat substitutes; fat and oils) in order to cover the varying nutrient needs in the population. The tip of the triangle is separated from the rest of the triangle and is called the 'rest group' or snacks ${ }^{(3)}$. The DQI is based on Flemish guidelines because there are no European guidelines yet. However, the Flemish recommendations are very similar to dietary guidelines in other countries, 
making these recommendations applicable for a European population of pre-schoolers ${ }^{(24)}$. The advantage of using one index is that it makes comparison between the different countries in the current study possible.

The food and beverage items of the FFQ were used to compute the total DQI and the four subcomponents. A study of Huybrechts et al. on the reproducibility and validity of a DQI in pre-schoolers assessed using an FFQ concluded that the FFQ-based DQI score is a reasonable estimate of diet quality when compared with $3 \mathrm{~d}$ diet records ${ }^{(7)}$. As mentioned before, the total DQI consists of four index subcomponents: dietary diversity, dietary quality, dietary equilibrium and the meal index.

Dietary diversity. At least one food item from each of the eight food groups of the Flemish active food triangle should be consumed on a daily basis ${ }^{(7,8,23)}$. For each food group (water, cereals, potatoes, fruit, vegetables, milk products, cheese and meat \& fish), the frequencies of the food items belonging to that food group were summed. Next, a diversity score of ' 1 ' was given if this sum was one or more; if not, diversity was scored ' 0 ' for that particular food group. The diversity scores of all food groups were summed, divided by the number of food groups (8) and multiplied by 100 .

Dietary quality. Each food item of the FFQ was scored ' -1 ', ' 0 ' or ' 1 ' depending on whether the food item of a certain food group was categorized in the lownutritious but energy-dense group $(-1)$, the intermediate group (0) or the preference group (1) of the Flemish active food triangle. This score was then multiplied by the amount (grams/millilitres) that was consumed for each food item in order to obtain the dietary quality score. All the individual food scores were then summed, divided by the total intake of all food items (grams/millilitres per day) and multiplied by 100 .

Dietary equilibrium. For each food group, the total daily intakes of all food items of that food group were summed. Then the daily intake of each food group was compared with the recommendation for that specific food group to calculate both adequacy and moderation ${ }^{(23)}$. If the daily intake met the minimum norm, a score of ' 1 ' was given for adequacy. When the daily intake of a food group did not meet the minimum norm, the adequacy score was calculated as follows: daily intake of the food group/minimum norm of the food group. Moderation was scored ' 0 ' if the maximum norm was not exceeded. If the maximum norm was exceeded, the score was calculated as follows: (maximum norm - daily intake of the food group)/maximum norm. If the daily intake of a food group was twice as many or more than the recommended maximum intake, a score of ' -1 ' was given for moderation. Equilibrium for each food group was calculated from the sum of adequacy and moderation. To determine the equilibrium score, an extra food group was added, more specifically snacks. Because this group consists mainly of energy-dense, low-nutritious food items, moderation of the snack group is very important. The total equilibrium score was the sum of all equilibrium scores divided by the total number of food groups (9) and multiplied by 100.

Meal index. Meal patterns were inquired in the FFQ. The meal index was calculated from the average amount of times breakfast, lunch and dinner were consumed, divided by 3 and multiplied by 100 .

Total DQI. The total DQI was calculated from the sum of the four index components, divided by 4 . High total DQI scores indicate better diet quality of the pre-schoolers than low scores, with $100 \%$ being a perfect score, meaning perfect compliance with the food-based dietary guidelines ${ }^{(7,8)}$. Results of the total DQI and the subcomponents are reported as percentages of maximum scores.

\section{Socio-economic status}

Education of the parents/caregivers was determined in the core questionnaire. The educational level of the mother was used as a SES indicator. Educational level has been identified as an important indicator for $\mathrm{SES}^{(25)}$. The educational level was dichotomized into lower $(\leq 14$ years of education) and high ( $>14$ years of education) SES, which distinguishes families with a mother who has completed medium or higher education, college or university training from other families ${ }^{(17)}$.

\section{Overweight}

Pre-schoolers' weight and height were measured by the ToyBox-study researchers as has been described elsewhere $^{(26)}$. Each measurement was conducted for a minimum of two times, then mean height and mean weight were calculated. Based on these measurements, the BMI was calculated. Next, the pre-schoolers were categorized into two categories based on the age- and sex-specific cut-off levels of Cole and Lobstein: being overweight or obese and not being overweight or obese ${ }^{(27)}$.

\section{Other sociodemographic variables}

Gender and date of birth were self-reported by one of the parents/caregivers of the pre-schoolers in the core questionnaire. Pre-school children's age was computed based on the date of birth and the date when the questionnaire was completed. All questionnaires are available on the ToyBox-website (www.toybox-study.eu) and in the ToyBox supplement issue ${ }^{(28)}$.

\section{Statistical analyses}

Descriptive statistics were performed using the statistical software package IBM SPSS Statistics for Windows, version 21.0. One-way (M)ANOVA were used to assess the country-specific differences in the descriptive statistics and the diet quality scores. Next, MANOVA were performed to assess differences in means of diet quality scores according to gender, SES and overweight. A three-way MANOVA was performed to investigate the interaction effects between 
gender, SES and overweight. Diet quality and differences in diet quality were tested in the total sample and stratified by country. The significance level was set at $P<0.05$.

\section{Results}

\section{Population characteristics}

The total and country-specific population characteristics are presented in Table 1. The total sample included 7063 pre-schoolers (mean age 4.8 (SD 0.4 ) years, $52.0 \%$ boys) from six European countries; $40 \cdot 1 \%$ had a mother with a lower level of education ( $\leq 14$ years of education) and $14.1 \%$ of the pre-schoolers were overweight or obese. Significant differences in SES were found between the different countries $(F=73.58, P<0.001)$. The Polish sample counted the fewest pre-schoolers of lower-SES mothers (21.0\%), the Greek sample the most (51.6\%). Also, significant differences in overweight were found between the six countries $(F=15.81, P<0.001)$. The Greek sample contained twice as many pre-school children with overweight (19.7\%) compared with the German sample $(10 \cdot 5 \%)$.

\section{Diet quality indices}

Table 2 provides an overview of the total and countryspecific scores on the total DQI and the subcomponents. Pre-schoolers of the total sample had a mean total DQI score of $68.3 \%$. Significant differences between countries were found $(F=65.42, \quad P<0.001)$. Greek pre-school children had the lowest total score $(65 \cdot 2 \%)$ and Belgian pre-schoolers the highest $(72 \cdot 3 \%)$. Also, significant differences between countries were found for each subscore (dietary diversity: $F=59.41, \quad P<0.001$; dietary quality: $F=121.89, \quad P<0.001$; dietary equilibrium: $F=22.52$, $P<0.001$; meal index: $F=83.12, P<0.001)$. The scores were especially low on dietary quality across all countries (56.5\%). Polish pre-school children scored the lowest on quality $(47.9 \%)$, Bulgarian pre-schoolers had the best score $(63.2 \%)$. The score on dietary diversity was $61.7 \%$ for the total sample. After stratification, this score ranged from $58.0 \%$ (Bulgaria) to $70.5 \%$ (Belgium). The dietary equilibrium score of the total sample was $65.4 \%$. After stratification, all scores were similar, ranging from $62 \cdot 2 \%$ (Bulgaria) to $66.7 \%$ (Belgium). The highest subscore was the meal index score (89.7\%), $72.9 \%$ of the pre-schoolers of the total sample consumed breakfast, lunch and dinner on a daily basis. Only $47.4 \%$ of Greek pre-schoolers consumed three meals every day, compared with $87 \cdot 0 \%$ of Polish pre-schoolers.

\section{Diet quality indices by gender}

Table 3 shows the results on differences in diet quality scores by gender. No significant differences by gender were found in the total DQI score. For dietary diversity, a significant difference in one country was found after stratification. Belgian male pre-schoolers scored better on diversity than female pre-schoolers. Female pre-school children of the total sample had a higher score on dietary quality than their male peers. This result was also seen in the Polish sample. For dietary equilibrium and the meal index, no significant differences by gender were found.

\section{Diet quality indices by educational level of the mother}

As presented in Table 4, scores on the diet quality indices differed significantly by SES. Pre-schoolers of high-SES backgrounds scored better on the total DQI than preschoolers of lower SES. After stratification, this result was also seen in four of the six countries (Belgium, Germany, Greece and Poland). The dietary diversity scores also varied by SES. Pre-school children of high-SES mothers had a higher score on diversity than their lower-SES peers. This result was also confirmed in the Bulgarian, German, Greek and Spanish samples. For dietary quality, scores were higher in pre-schoolers of high-SES backgrounds than in preschoolers from lower-SES mothers. After stratification, this result was seen in all countries, except for Bulgaria. Also for dietary equilibrium, higher scores were found for high-SES pre-school children compared with their lower-SES peers. This result was confirmed in three countries (Belgium, Germany and Greece). Finally, also the scores on meal index were higher in pre-schoolers of high-SES backgrounds than pre-schoolers of lower-SES mothers. After stratification, this was found only in the German sample.

Table 1 Characteristics of participants of the total sample and of each country separately. European pre-schoolers (aged 3.5-5.5 years) and their parents/caregivers ( $n$ 7063), ToyBox-study, May-June 2012

\begin{tabular}{|c|c|c|c|c|c|c|c|}
\hline & Total & Belgium & Bulgaria & Germany & Greece & Poland & Spain \\
\hline$n$ & 7063 & 945 & 783 & 1267 & 1807 & 1388 & 873 \\
\hline \multicolumn{8}{|l|}{ Age (years) } \\
\hline Mean & $4 \cdot 8$ & 4.4 & 4.9 & $4 \cdot 6$ & 4.9 & 4.9 & 4.9 \\
\hline SD & 0.4 & 0.5 & 0.3 & 0.6 & 0.3 & 0.3 & 0.3 \\
\hline Gender (\% male) & $52 \cdot 0$ & $52 \cdot 3$ & $50 \cdot 2$ & $51 \cdot 6$ & $51 \cdot 3$ & 53.0 & $54 \cdot 2$ \\
\hline SES (\% lower SES)† & $40 \cdot 1$ & $35 \cdot 1$ & $40 \cdot 7$ & $51 \cdot 2$ & $51 \cdot 6$ & $21 \cdot 0$ & $35 \cdot 6$ \\
\hline BMI (\% overweight) $)$ & $14 \cdot 1$ & 11.8 & $15 \cdot 1$ & $10 \cdot 5$ & 19.7 & $12 \cdot 7$ & $15 \cdot 5$ \\
\hline
\end{tabular}

SES, socio-economic status.

†SES indicator is years of school education of the mother: lower, mother of the child has $\leq 14$ years of education. flncluding obese. 
Table 2 Mean diet quality indices (\%) of the total sample and each country separately. European pre-schoolers (aged 3.5-5.5 years) and their parents/caregivers ( $n$ 7063), ToyBox-study, May-June 2012

\begin{tabular}{|c|c|c|c|c|c|c|c|}
\hline & Total & Belgium & Bulgaria & Germany & Greece & Poland & Spain \\
\hline Dietary diversity & $61 \cdot 7$ & 70.5 & 58.0 & 61.4 & 58.7 & $61 \cdot 6$ & $62 \cdot 6$ \\
\hline Dietary quality & $56 \cdot 5$ & $57 \cdot 7$ & 63.2 & $60 \cdot 7$ & $55 \cdot 3$ & 47.9 & 59.5 \\
\hline Dietary equilibrium & 65.4 & $66 \cdot 7$ & $62 \cdot 2$ & $66 \cdot 3$ & $66 \cdot 5$ & $65 \cdot 1$ & 63.7 \\
\hline Meal index & 89.7 & 94.1 & 92.9 & $92 \cdot 0$ & $80 \cdot 4$ & $95 \cdot 6$ & 88.5 \\
\hline Meal index $2 \dagger$ & $72 \cdot 9$ & 81.0 & 84.8 & $76 \cdot 2$ & $47 \cdot 4$ & 87.0 & 78.9 \\
\hline Total DQI & $68 \cdot 3$ & $72 \cdot 3$ & $69 \cdot 1$ & $70 \cdot 1$ & $65 \cdot 2$ & 67.5 & $68 \cdot 6$ \\
\hline
\end{tabular}

DQI, Diet Quality Index ${ }^{(7)}$.

†Percentage of pre-schoolers who consume breakfast, lunch and dinner every day.

Table 3 Differences in means of diet quality indices (\%) between boys and girls in the total sample and the six European countries separately (MANOVA). European pre-schoolers (aged 3.5-5.5 years) and their parents/caregivers ( $n$ 7063), ToyBox-study, May-June 2012

\begin{tabular}{|c|c|c|c|c|c|c|c|c|c|c|c|c|c|c|c|}
\hline & \multirow[b]{2}{*}{ Gender } & \multicolumn{2}{|c|}{ Total } & \multicolumn{2}{|c|}{ Belgium } & \multicolumn{2}{|c|}{ Bulgaria } & \multicolumn{2}{|c|}{ Germany } & \multicolumn{2}{|c|}{ Greece } & \multicolumn{2}{|c|}{ Poland } & \multicolumn{2}{|c|}{ Spain } \\
\hline & & Mean & $F$ & Mean & $F$ & Mean & $F$ & Mean & $F$ & Mean & $F$ & Mean & $F$ & Mean & $F$ \\
\hline Multivariate & & & $3.48^{\star *}$ & & 1.92 & & 0.81 & & 0.41 & & 0.68 & & $2 \cdot 63^{*}$ & & 0.59 \\
\hline Dietary diversity & $\begin{array}{l}\text { Male } \\
\text { Female }\end{array}$ & $\begin{array}{l}61 \cdot 8 \\
61 \cdot 7\end{array}$ & 0.02 & $\begin{array}{l}71.5 \\
69.4\end{array}$ & $4 \cdot 06^{*}$ & $\begin{array}{l}58.5 \\
57.4\end{array}$ & 0.64 & $\begin{array}{l}61.4 \\
61.5\end{array}$ & 0.01 & $\begin{array}{l}58 \cdot 8 \\
58 \cdot 6\end{array}$ & 0.08 & $\begin{array}{l}60 \cdot 7 \\
62 \cdot 5\end{array}$ & $3 \cdot 11$ & $\begin{array}{l}62 \cdot 2 \\
63 \cdot 1\end{array}$ & 0.71 \\
\hline Dietary quality & $\begin{array}{l}\text { Male } \\
\text { Female }\end{array}$ & $\begin{array}{l}55 \cdot 9 \\
57.2\end{array}$ & $9 \cdot 84^{\star *}$ & $\begin{array}{l}57.5 \\
57.9\end{array}$ & 0.11 & $\begin{array}{l}62 \cdot 4 \\
64 \cdot 0\end{array}$ & $2 \cdot 37$ & $\begin{array}{l}60 \cdot 2 \\
61 \cdot 4\end{array}$ & 1.38 & $\begin{array}{l}54.8 \\
55 \cdot 8\end{array}$ & 1.56 & $\begin{array}{l}46 \cdot 9 \\
49 \cdot 1\end{array}$ & $4 \cdot 42^{*}$ & $\begin{array}{l}59.0 \\
60.0\end{array}$ & 0.89 \\
\hline Dietary equilibrium & $\begin{array}{l}\text { Male } \\
\text { Female }\end{array}$ & $\begin{array}{l}65 \cdot 5 \\
65 \cdot 3\end{array}$ & 0.52 & $\begin{array}{l}67 \cdot 3 \\
66 \cdot 1\end{array}$ & $2 \cdot 56$ & $\begin{array}{l}62 \cdot 1 \\
62 \cdot 4\end{array}$ & 0.14 & $\begin{array}{l}66 \cdot 3 \\
66 \cdot 2\end{array}$ & 0.01 & $\begin{array}{l}66 \cdot 6 \\
66.5\end{array}$ & 0.01 & $\begin{array}{l}65 \cdot 1 \\
65.0\end{array}$ & 0.05 & $\begin{array}{l}63.8 \\
63.6\end{array}$ & $0 \cdot 10$ \\
\hline Meal index & $\begin{array}{l}\text { Male } \\
\text { Female }\end{array}$ & $\begin{array}{l}90.0 \\
89.4\end{array}$ & $1 \cdot 22$ & $\begin{array}{l}94.9 \\
93.3\end{array}$ & $2 \cdot 31$ & $\begin{array}{l}92 \cdot 5 \\
93 \cdot 4\end{array}$ & 0.28 & $\begin{array}{l}92.1 \\
91.9\end{array}$ & 0.03 & $\begin{array}{l}80.9 \\
79.9\end{array}$ & 0.53 & $\begin{array}{l}96 \cdot 1 \\
95 \cdot 1\end{array}$ & $1 \cdot 38$ & $\begin{array}{l}88 \cdot 3 \\
88 \cdot 7\end{array}$ & 0.05 \\
\hline Total DQI & $\begin{array}{l}\text { Male } \\
\text { Female }\end{array}$ & $\begin{array}{l}68 \cdot 3 \\
68 \cdot 4\end{array}$ & 0.14 & $\begin{array}{l}72 \cdot 8 \\
71 \cdot 7\end{array}$ & 3.50 & $\begin{array}{l}68.9 \\
69 \cdot 3\end{array}$ & 0.34 & $\begin{array}{l}70 \cdot 0 \\
70 \cdot 2\end{array}$ & 0.17 & $\begin{array}{l}65 \cdot 3 \\
65 \cdot 2\end{array}$ & 0.04 & $\begin{array}{l}67 \cdot 2 \\
67.9\end{array}$ & 1.58 & $\begin{array}{l}68 \cdot 3 \\
68 \cdot 8\end{array}$ & 0.55 \\
\hline
\end{tabular}

DQI, Diet Quality Index ${ }^{(7)}$

${ }^{\star} P<0.05,{ }^{\star \star} P<0.01$

Table 4 Differences in means of diet quality indices (\%) between lower and high SES in the total sample and the six European countries separately (MANOVA). European pre-schoolers (aged 3.5-5.5 years) and their parents/caregivers ( $n$ 7063), ToyBox-study, May-June 2012

\begin{tabular}{|c|c|c|c|c|c|c|c|c|c|c|c|c|c|c|c|}
\hline & \multirow[b]{2}{*}{ SES† } & \multicolumn{2}{|c|}{ Total } & \multicolumn{2}{|c|}{ Belgium } & \multicolumn{2}{|c|}{ Bulgaria } & \multicolumn{2}{|c|}{ Germany } & \multicolumn{2}{|c|}{ Greece } & \multicolumn{2}{|c|}{ Poland } & \multicolumn{2}{|c|}{ Spain } \\
\hline & & Mean & $F$ & Mean & $F$ & Mean & $F$ & Mean & $F$ & Mean & $F$ & Mean & $F$ & Mean & $F$ \\
\hline Multivariate & & & $23 \cdot 94^{\star \star \star}$ & & $5 \cdot 69^{\star \star \star}$ & & $2 \cdot 21$ & & $12 \cdot 40^{\star \star \star}$ & & $11 \cdot 88^{\star \star \star}$ & & $4.65^{\star \star}$ & & $3.56^{\star *}$ \\
\hline Dietary diversity & $\begin{array}{l}\text { Lower } \\
\text { High }\end{array}$ & $\begin{array}{l}59.6 \\
63.6\end{array}$ & $68 \cdot 70^{\star \star \star}$ & $\begin{array}{l}69.5 \\
71.5\end{array}$ & $3 \cdot 27$ & $\begin{array}{l}56 \cdot 1 \\
59 \cdot 7\end{array}$ & $5.52^{*}$ & $\begin{array}{l}58.7 \\
64.9\end{array}$ & $29 \cdot 25^{\star \star \star}$ & $\begin{array}{l}57.5 \\
60.7\end{array}$ & $11 \cdot 08^{\star \star}$ & $\begin{array}{l}60 \cdot 2 \\
62 \cdot 3\end{array}$ & $2 \cdot 46$ & $\begin{array}{l}60 \cdot 1 \\
63.9\end{array}$ & $9 \cdot 80^{* *}$ \\
\hline Dietary quality & $\begin{array}{l}\text { Lower } \\
\text { High }\end{array}$ & $\begin{array}{l}55 \cdot 5 \\
57 \cdot 8\end{array}$ & $23.94^{\star \star \star}$ & $\begin{array}{l}54 \cdot 6 \\
59 \cdot 8\end{array}$ & $18 \cdot 24^{\star \star \star}$ & $\begin{array}{l}62 \cdot 6 \\
64 \cdot 2\end{array}$ & 1.95 & $\begin{array}{l}58 \cdot 8 \\
63.5\end{array}$ & $18 \cdot 90^{\star \star \star}$ & $\begin{array}{l}53 \cdot 8 \\
57 \cdot 8\end{array}$ & $27 \cdot 11^{\star * *}$ & $\begin{array}{l}43 \cdot 7 \\
49 \cdot 2\end{array}$ & $16 \cdot 14^{\star \star \star}$ & $\begin{array}{l}58 \cdot 7 \\
60 \cdot 9\end{array}$ & $4.07^{\star}$ \\
\hline Dietary equilibrium & $\begin{array}{l}\text { Lower } \\
\text { High }\end{array}$ & $\begin{array}{l}64 \cdot 6 \\
66 \cdot 3\end{array}$ & $29 \cdot 09^{\star \star \star}$ & $\begin{array}{l}65 \cdot 3 \\
67 \cdot 7\end{array}$ & $8 \cdot 27^{\star *}$ & $\begin{array}{l}62 \cdot 9 \\
62 \cdot 4\end{array}$ & 0.38 & $\begin{array}{l}64 \cdot 7 \\
68 \cdot 2\end{array}$ & $25 \cdot 15^{\star \star \star}$ & $\begin{array}{l}65 \cdot 5 \\
68 \cdot 3\end{array}$ & $23 \cdot 41^{\star \star \star}$ & $\begin{array}{l}63.9 \\
65.5\end{array}$ & 3.48 & $\begin{array}{l}63 \cdot 5 \\
64 \cdot 2\end{array}$ & 0.51 \\
\hline Meal index & $\begin{array}{l}\text { Lower } \\
\text { High }\end{array}$ & $\begin{array}{l}89 \cdot 0 \\
90 \cdot 9\end{array}$ & $9 \cdot 78^{\star *}$ & $\begin{array}{l}93.0 \\
94.7\end{array}$ & 1.78 & $\begin{array}{l}92 \cdot 8 \\
93.5\end{array}$ & 0.18 & $\begin{array}{l}91.6 \\
94.0\end{array}$ & $3 \cdot 88^{*}$ & $\begin{array}{l}82 \cdot 1 \\
79 \cdot 6\end{array}$ & $2 \cdot 82$ & $\begin{array}{l}94 \cdot 6 \\
96 \cdot 2\end{array}$ & 1.93 & $\begin{array}{l}90 \cdot 3 \\
88 \cdot 1\end{array}$ & 0.99 \\
\hline Total DQI & $\begin{array}{l}\text { Lower } \\
\text { High }\end{array}$ & $\begin{array}{l}67 \cdot 2 \\
69 \cdot 6\end{array}$ & $79 \cdot 78^{\star \star \star}$ & $\begin{array}{l}70 \cdot 6 \\
73 \cdot 4\end{array}$ & $17 \cdot 75^{\star \star \star}$ & $\begin{array}{l}68 \cdot 6 \\
70 \cdot 0\end{array}$ & $3 \cdot 31$ & $\begin{array}{l}68 \cdot 5 \\
72 \cdot 7\end{array}$ & $45 \cdot 28^{\star \star \star}$ & $\begin{array}{l}64 \cdot 7 \\
66 \cdot 6\end{array}$ & $10 \cdot 57^{\star \star}$ & $\begin{array}{l}65 \cdot 6 \\
68 \cdot 3\end{array}$ & $14 \cdot 22^{\star \star \star}$ & $\begin{array}{l}68 \cdot 1 \\
69 \cdot 3\end{array}$ & $2 \cdot 10$ \\
\hline
\end{tabular}

SES, socio-economic status; DQI, Diet Quality Index ${ }^{(7)}$.

${ }^{*} P<0.05,{ }^{* *} P<0.01,{ }^{* * *} P<0.001$.

TSES indicator is years of school education of the mother: lower, mother of the child has $\leq 14$ years of education; high, mother of the child has $>14$ years of education.

\section{Diet quality indices by overweight}

Table 5 presents the results on differences in scores on diet quality indices by overweight. No differences in scores on total DQI were seen based on overweight status, neither in the total sample nor after stratification. Pre-schoolers with overweight had significantly lower scores on dietary diversity than pre-schoolers without overweight in the total sample. For dietary quality, no significant differences by overweight were found. Bulgarian pre-school children with overweight had higher scores on dietary equilibrium than their peers with a normal weight. This result was not found in other 
Table 5 Differences in means of diet quality indices (\%) between normal-weight and overweight pre-schoolers in the total sample and the six European countries separately (MANOVA). European pre-schoolers (aged 3.5-5.5 years) and their parents/caregivers ( $n$ 7063), ToyBox-study, May-June 2012

\begin{tabular}{|c|c|c|c|c|c|c|c|c|c|c|c|c|c|c|c|}
\hline & \multirow[b]{2}{*}{ Overweight $†$} & \multicolumn{2}{|c|}{ Total } & \multicolumn{2}{|c|}{ Belgium } & \multicolumn{2}{|c|}{ Bulgaria } & \multicolumn{2}{|c|}{ Germany } & \multicolumn{2}{|c|}{ Greece } & \multicolumn{2}{|c|}{ Poland } & \multicolumn{2}{|c|}{ Spain } \\
\hline & & Mean & $F$ & Mean & $F$ & Mean & $F$ & Mean & $F$ & Mean & $F$ & Mean & $F$ & Mean & $F$ \\
\hline Multivariate & & & $3 \cdot 37^{\star *}$ & & 0.99 & & 1.60 & & 1.39 & & 1.48 & & 0.99 & & 0.60 \\
\hline Dietary diversity & $\begin{array}{l}\text { Yes } \\
\text { No }\end{array}$ & $\begin{array}{l}60 \cdot 6 \\
61.9\end{array}$ & $4 \cdot 32^{\star}$ & $\begin{array}{l}69 \cdot 1 \\
70 \cdot 7\end{array}$ & 0.93 & $\begin{array}{l}59 \cdot 8 \\
57 \cdot 6\end{array}$ & 1.09 & $\begin{array}{l}58 \cdot 9 \\
61.6\end{array}$ & $2 \cdot 16$ & $\begin{array}{l}58.4 \\
58.8\end{array}$ & $0 \cdot 15$ & $\begin{array}{l}59.7 \\
61.9\end{array}$ & $2 \cdot 18$ & $\begin{array}{l}63.0 \\
62.3\end{array}$ & $0 \cdot 18$ \\
\hline Dietary quality & $\begin{array}{l}\text { Yes } \\
\text { No }\end{array}$ & $\begin{array}{l}57 \cdot 2 \\
56 \cdot 3\end{array}$ & 1.80 & $\begin{array}{l}58.8 \\
57.5\end{array}$ & 0.57 & $\begin{array}{l}63.0 \\
63.3\end{array}$ & 0.03 & $\begin{array}{l}62 \cdot 2 \\
60 \cdot 6\end{array}$ & 0.84 & $\begin{array}{l}56 \cdot 6 \\
55 \cdot 1\end{array}$ & $2 \cdot 57$ & $\begin{array}{l}47 \cdot 7 \\
48 \cdot 0\end{array}$ & 0.03 & $\begin{array}{l}61 \cdot 2 \\
59 \cdot 2\end{array}$ & 2.08 \\
\hline Dietary equilibrium & $\begin{array}{l}\text { Yes } \\
\text { No }\end{array}$ & $\begin{array}{l}65 \cdot 6 \\
65.4\end{array}$ & 0.26 & $\begin{array}{l}65 \cdot 7 \\
66 \cdot 8\end{array}$ & 1.05 & $\begin{array}{l}64.5 \\
61.9\end{array}$ & $4 \cdot 71^{*}$ & $\begin{array}{l}67 \cdot 0 \\
66 \cdot 1\end{array}$ & 0.63 & $\begin{array}{l}66 \cdot 2 \\
66 \cdot 9\end{array}$ & $1 \cdot 10$ & $\begin{array}{l}65.4 \\
65.0\end{array}$ & 0.15 & $\begin{array}{l}64.0 \\
63.8\end{array}$ & 0.03 \\
\hline Meal index & $\begin{array}{l}\text { Yes } \\
\text { No }\end{array}$ & $\begin{array}{l}87.9 \\
90.0\end{array}$ & $6 \cdot 38^{*}$ & $\begin{array}{l}92.5 \\
94.4\end{array}$ & $1 \cdot 31$ & $\begin{array}{l}91.4 \\
93.2\end{array}$ & 0.56 & $\begin{array}{l}92.7 \\
91.7\end{array}$ & 0.18 & $\begin{array}{l}80 \cdot 0 \\
80 \cdot 2\end{array}$ & 0.03 & $\begin{array}{l}94.5 \\
95.8\end{array}$ & 0.85 & $\begin{array}{l}89.4 \\
88.7\end{array}$ & 0.07 \\
\hline Total DQI & $\begin{array}{l}\text { Yes } \\
\text { No }\end{array}$ & $\begin{array}{l}67 \cdot 8 \\
68 \cdot 4\end{array}$ & $2 \cdot 71$ & $\begin{array}{l}71 \cdot 5 \\
72 \cdot 3\end{array}$ & 0.88 & $\begin{array}{l}69 \cdot 7 \\
69 \cdot 0\end{array}$ & 0.45 & $\begin{array}{l}70 \cdot 2 \\
70 \cdot 0\end{array}$ & 0.03 & $\begin{array}{l}65 \cdot 3 \\
65 \cdot 3\end{array}$ & 0.00 & $\begin{array}{l}66 \cdot 8 \\
67.7\end{array}$ & 1.07 & $\begin{array}{l}69.4 \\
68.5\end{array}$ & 0.84 \\
\hline
\end{tabular}

DQI, Diet Quality Index ${ }^{(7)}$.

${ }^{\star} P<0.05,{ }^{\star \star} P<0.01$.

†Including obesity.

Table 6 Interaction effects between gender, SES and overweight $†$ on diet quality indices in the total sample (three-way MANOVA). European pre-schoolers (aged 3.5-5.5 years) and their parents/ caregivers ( $n$ 7063), ToyBox-study, May-June 2012

\begin{tabular}{|c|c|c|c|c|}
\hline & $\begin{array}{l}\text { Gender } \\
\times \text { SES }\end{array}$ & $\begin{array}{l}\text { Gender } \times \\
\text { overweight }\end{array}$ & $\begin{array}{c}\text { SES } \times \\
\text { overweight }\end{array}$ & $\begin{array}{l}\text { Gender } \times \\
\text { SES } \times \\
\text { overweight }\end{array}$ \\
\hline & $F$ & $F$ & $F$ & $F$ \\
\hline Multivariate & 1.66 & 0.78 & 0.52 & 1.41 \\
\hline Dietary diversity & 3.51 & 0.40 & 0.79 & 1.95 \\
\hline Dietary quality & 2.25 & 0.59 & 0.11 & 1.07 \\
\hline $\begin{array}{l}\text { Dietary } \\
\text { equilibrium }\end{array}$ & 2.87 & 1.61 & 0.53 & 3.76 \\
\hline Meal index & 0.91 & 0.15 & 0.85 & $1 \cdot 15$ \\
\hline Total DQI & $6 \cdot 00^{*}$ & 0.28 & 0.04 & $4 \cdot 76^{*}$ \\
\hline
\end{tabular}

SES, socio-economic status; DQI, Diet Quality Index ${ }^{(7)}$.

${ }^{*} P<0.05$.

†Including obesity.

countries or in the total sample. For the meal index, only in the total sample was a significant difference found. Pre-school children with overweight scored worse on the meal index than pre-schoolers without overweight.

\section{Interaction between gender, socio-economic status and overweight}

Table 6 presents the results on the interaction effects between gender, SES and overweight. Only limited interaction effects were found. Both in the overweight preschoolers as in the normal-weight pre-school children, pre-schoolers of high-SES backgrounds had better total DQI scores than lower-SES pre-schoolers. In overweight pre-schoolers, gender differences were dependent on SES: in pre-schoolers of lower-SES backgrounds, boys had better scores on total diet quality than girls, while in highSES pre-schoolers, girls had better total diet quality scores than boys. In normal-weight pre-school children gender differences were not dependent on SES.

\section{Discussion}

The aim of the present study was to investigate the diet quality in pre-schoolers of six European countries based on the DQI and the differences in diet quality according to gender, SES and overweight. The first objective of the study was to provide an overview of the diet quality of European pre-schoolers based on the total DQI and the four subcomponents. A high total DQI score indicates a better diet quality of the pre-schoolers than a low score, with $100 \%$ being a perfect score ${ }^{(8,9)}$. Results of the total DQI and the subcomponents are reported as percentages of maximum scores. There was still a lot of room for improvement in the mean score on total diet quality (68.3\%). Similar results for total diet quality were found in Flemish pre-schoolers in a study of Huybrechts et al. $(72 \%)^{(7)}$.

When looking into the four subcomponents, it was found that the highest scores were achieved for the meal index ( $89 \cdot 7 \%)$. Most pre-schoolers consumed breakfast, lunch and dinner every day. The lowest scores were found in dietary quality $(56.5 \%)$. This means that the subcomponent dietary quality appeared to be the main problem in European pre-schoolers. In other words, preschoolers or their parents/caregivers made unhealthy food choices since especially energy-dense, low-nutritious food items (such as sweet snacks or sugared beverages) were consumed instead of highly nutritious food items (such as vegetables). However, also rather low scores were found on dietary diversity and dietary equilibrium. So pre-school children do not have a lot of variety in their diet and do not have an adequate but moderate intake of each food group. In other words, they did not reach the minimum norm or they exceeded the maximum recommendation. Minimal differences were found between the different countries. So it seemed that a similar pattern in diet quality can be found in all six countries. Similar results were found in a study of diet quality based on the DQI in Flemish pre-schoolers in which dietary quality was the lowest 
subcomponent and pre-schoolers had the highest scores on the meal index ${ }^{(7)}$.

A second objective was to provide insight into differences in diet quality scores according to SES, gender and overweight status. Very clear differences in diet quality scores were found by SES. Pre-schoolers of lower-SES mothers had lower scores on total diet quality and all subcomponents compared with pre-school children of high-SES backgrounds. The country-specific results in much smaller samples supported this finding, to a large extent in Germany and much less in Bulgaria. A study on Greek pre-schoolers using the HEI also found lower diet quality in pre-schoolers of mothers with lower educational status $^{(4)}$. This is an important finding given that the scores were already low in the general pre-schoolers group. Previous studies already found higher consumption of fat, sweets and soft drinks, and lower fruit and vegetable intakes, in children of lower-SES backgrounds ${ }^{(15-17)}$. However, the current study indicates that the problem is much larger. It appeared that already in very young children lower-SES mothers are not able to provide a good diet quality and this was consistent for all four subcomponents of the total DQI. Several explanations can be provided for the differences in diet quality according to SES. First, parents play an important role in food consumption of young children. It has been found that lower-SES mothers consume less fruit and vegetables and more soft drinks compared with high-SES mothers, which is a significant factor given the important influence of parental role modelling on children's dietary behaviours ${ }^{(29)}$. Also a difference in other parenting practices between high- and lower-SES mothers can explain the differences in diet quality according to SES. Lower-SES mothers often lack skills to impose restrictions on the consumption of unhealthy foods and skills to reinforce positive behaviour ${ }^{(29)}$. In addition, high-SES parents often take health more into account than lower-SES parents ${ }^{(29)}$. Furthermore, lower-SES parents are more difficult to reach with health messages ${ }^{(30)}$. In lower-SES parents, knowledge problems might occur as the educational level of the mother was used as an indicator for SES. Kant and Graubard indicated that 'education may be linked to acquisition, understanding, and implementation of knowledge about desirable dietary behaviours' (p. 690) ${ }^{(31)}$. Future interventions to improve the diet quality should pay extra attention to this subgroup of pre-schoolers.

Unlike the significant differences by SES, no differences in total diet quality were found between boys and girls. Only in the subcomponent dietary quality were differences by gender found, with female pre-schoolers having better scores than their male peers. Also, the present study showed little differences in diet quality scores in terms of overweight/obesity status. Although a difference in diet quality was expected as unhealthy choices can lead to overweight or obesity ${ }^{(1,3,12,18)}$, we did not find this in the current study. The lack of difference by overweight/ obesity status can possibly be explained by the young age of the children. The negative health effects of an unhealthy diet might not be seen yet at such a young age. However, we know that tracking of the unhealthy diet quality may lead to an increase of overweight in later life. A review by Craigie et al. reported evidence of eating patterns tracking between childhood and adulthood ${ }^{(2)}$. In addition, an unhealthy diet can also cause other health problems besides overweight or obesity. Parents may think that their child is healthy when there is no weight problem, but other health problems, such as diabetes, may occur in later life because of a poor diet quality in early childhood.

The present study holds several strengths. To our knowledge, it is the first study that examined the diet quality of pre-schoolers in European countries based on the DQI and its relationship with SES, gender and weight status. In addition, by using the validated DQI to assess diet quality, also the complexity and the multidimensional nature of food consumption patterns are covered ${ }^{(8,13)}$. Another study strength was the large sample of pre-schoolers from six European countries and the standardized data collection protocol across the different countries.

The current study has some limitations. The FFQ was filled in by parents/caregivers, so under-reporting and over-reporting might be a bias caused by socially desirable answers ${ }^{(32)}$. This was partially covered by ensuring anonymity. In addition, González-Gil et al. have studied the reliability of primary caregivers' reports and concluded that a primary caregivers' questionnaire is a reliable tool to assess sociodemographic characteristics, perinatal factors and lifestyle behaviours of pre-school children and their families participating in the ToyBox-study ${ }^{(33)}$. An FFQ is not as accurate in evaluating food intake as a multiple diet record $^{(7)}$. However, the FFQ used in the ToyBox-study is based on a previously validated FFQ developed by Huybrechts et l $^{(22)}$. As mentioned before, the FFQ-based DQI score is a reasonable estimate of diet quality when compared with $3 \mathrm{~d}$ diet records and an appropriate indicator to rank individuals according to their diet quality ${ }^{(7)}$. The DQI of Huybrechts et al. is exclusively based on food-based guidelines and not on nutrient-based guidelines, unlike the original Diet Quality Index developed for the US population ${ }^{(8)}$. However, benefits of a food-based guideline index include the possible use of an FFQ and does not require a link with food composition tables, avoiding additional measurement errors inherent to food composition data and matching with food consumption data ${ }^{(8)}$. The encoding strategy used to avoid missing scores may have affected the accuracy of the findings. A maximum of $3 \%$ of missing values was found for frequency of the FFQ items. Regarding portion size, for some items up to half of the participants had a missing value. However, most items had lower percentages (less than 10\%) of missing values. Nevertheless, the encoding strategy used in the current study has also been used in the validation study of the FFQ of Huybrechts 
et al., which means that this is a widely used method to deal with missing variables in an $\mathrm{FFQ}^{(22)}$. Since SES was assessed only by the educational level of the mother, preschool children living in a family with a father having a higher educational level than the mother were assessed as having a lower educational status. However, maternal education is often seen as more influential for the child than education of the father given that mothers are often the primary caregiver ${ }^{(34,35)}$. This was also found in a study of De Coen et al., in which only maternal education was found as a risk factor for overweight in pre-school children and no significant results were found for paternal education $^{(36)}$. We acknowledge that the ToyBox-sample is not a fully representative European sample, due to sampling in specific regions in each country. However, limited differences can be found between regions within European countries. Samples included pre-schoolers of low-, medium- and high-SES backgrounds and in each kindergarten (almost) complete classes were included. The samples can give a fair approximation of the average situation in each country. The procedure of sampling in specific regions has also been used in several other European studies such as HELENA (Healthy Lifestyle in Europe by Nutrition in Adolescence) and ENERGY (EuropeaN Energy balance Research to prevent excessive weight Gain among Youth) ${ }^{(37,38)}$. As the present study was a cross-sectional study, no causality in relationships could be identified. Longitudinal data are needed to study the change in diet quality throughout childhood.

\section{Conclusion}

The total diet quality of European pre-schoolers is rather low. Especially the subcomponent dietary quality, which focuses on the quality of the selected food products, appeared to be the main problem as pre-schoolers or their parents/caregivers made unhealthy food choices. However, scores on dietary variety and dietary equilibrium were also low. Differences in diet quality according to gender and overweight/obesity status were not found. However, differences in diet quality scores by SES were found. Pre-schoolers of high-SES backgrounds had higher scores on total diet quality and all subcomponents than their lower-SES peers. So, it appeared that even in very young children lower-SES mothers are not able to provide a good diet quality and this was consistent for all four subcomponents of the total DQI. An optimal food intake should be enhanced, especially in pre-schoolers of lower-SES backgrounds.

\section{Acknowledgements}

Financial support: The ToyBox-study is funded by the Seventh Framework Programme (CORDIS FP7) of the European Commission under grant agreement number
245200. The sponsor had no role in the design or conduct of the study, the collection, management, analysis or interpretation of the data, or the preparation, review and approval of the manuscript. The content of this article reflects only the authors' views and the European Community is not liable for any use that may be made of the information contained herein. Conflict of interest: None. Authorship: All authors, except for I.H., B.D., W.V.L. and A.-S.P., participated in the ToyBox-study and in the study design. All authors read, critically reviewed the manuscript and approved the final manuscript. A.-S.P. wrote the manuscript. Ethics of buman subject participation: The ToyBox-study was approved by ethics committees in all six European countries, in line with national regulations. The ToyBox-study group consists of the following. Co-ordinator: Yannis Manios; Steering Committee: Yannis Manios, Berthold Koletzko, Ilse De Bourdeaudhuij, Mai Chin A Paw, Luis Moreno, Carolyn Summerbell, Tim Lobstein, Lieven Annemans, Goof Buijs; External Advisors: John Reilly, Boyd Swinburn, Dianne Ward; Harokopio University (Greece): Yannis Manios, Odysseas Androutsos, Eva Grammatikaki, Christina Katsarou, Eftychia Apostolidou, Eirini Efstathopoulou; Ludwig-Maximilians-Universität-München (Germany): Berthold Koletzko, Kristin Duvinage, Sabine Ibrügger, Angelika Strauß, Birgit Herbert, Julia Birnbaum, Annette Payr, Christine Geyer; Ghent University (Belgium), Department of Movement and Sports Sciences: Ilse De Bourdeaudhuij, Greet Cardon, Marieke De Craemer, Ellen De Decker and Department of Public Health: Lieven Annemans, Stefaan De Henauw, Lea Maes, Carine Vereecken, Jo Van Assche, Lore Pil; VU University Medical Center, EMGO Institute for Health and Care Research (the Netherlands): Mai Chin A Paw, Saskia te Velde; University of Zaragoza (Spain): Luis Moreno, Theodora Mouratidou, Juan Fernandez, Maribel Mesana, Pilar De Miguel-Etayo, Esther González, Luis Gracia-Marco, Beatriz Oves; Oslo and Akershus University College of Applied Sciences (Norway): Agneta Yngve, Susanna Kugelberg, Christel Lynch, Annhild Mosdøl; University of Durham (UK): Carolyn Summerbell, Helen Moore, Wayne Douthwaite, Catherine Nixon; State Institute of Early Childhood Research (Germany): Susanne Kreichauf, Andreas Wildgruber; Children's Memorial Health Institute (Poland): Piotr Socha, Zbigniew Kulaga, Kamila Zych, Magdalena Góźdź, Beata Gurzkowska, Katarzyna Szott; Medical University of Varna (Bulgaria): Violeta Iotova, Mina Lateva, Natalya Usheva, Sonya Galcheva, Vanya Marinova, Zhaneta Radkova, Nevyana Feschieva; International Association for the Study of Obesity (UK): Tim Lobstein, Andrea Aikenhead; National Institute for Health Promotion and Disease Prevention (the Netherlands): Goof Buijs, Annemiek Dorgelo, Aviva Nethe, Jan Jansen; AOK-Verlag (Germany): Otto Gmeiner, Jutta Retterath, Julia Wildeis, Axel Günthersberger; Roehampton University (UK): Leigh Gibson; University of Luxembourg (Luxembourg): Claus Voegele. 


\section{References}

1. Huybrechts I \& De Henauw S (2007) Energy and nutrient intake by pre-school children in Flanders-Belgium. BrJ Nutr 98, 600-610.

2. Craigie AM, Lake AA, Kelly SA et al. (2011) Tracking of obesity-related behaviours from childhood to adulthood: a systematic review. Maturitas 70, 266-284.

3. Huybrechts I, Matthys C, Vereecken C et al. (2008) Food intakes by preschool children in Flanders compared with dietary guidelines. Int J Environ Res Public Health 5 , 243-257.

4. Manios Y, Kourlaba G, Kondaki K et al. (2009) Diet quality of preschoolers in Greece based on the Healthy Eating Index: the GENESIS study. J Am Diet Assoc 109, 616-623.

5. Royo-Bordonada MA, Gorgojo L, Martín-Moreno JM et al. (2003) Spanish children's diet: compliance with nutrient and food intake guidelines. Eur J Clin Nutr 57, 930-939.

6. Kersting M, Alexy U, Kroke A et al. (2004) Nutrition of children and adolescents. Results of the DONALD Study. Bundesgesundheitsblatt Gesundheitsforschung Gesundheitsschutz 57, 213-218.

7. Huybrechts I, Vereecken C, De Bacquer D et al. (2010) Reproducibility and validity of a diet quality index for children assessed using a FFQ. Br J Nutr 104, 135-144.

8. Huybrechts I, Vereecken C, Vyncke K et al. (2013) The 'Diet Quality Index' and its applications. In Diet Quality: $A n$ Evidence-Based Approach, vol. 2, pp. 301-314 [VR Preedy, L-A Hunter and VB Patel, editors]. New York: Springer.

9. Nicklaus S (2009) Development of food variety in children. Appetite 52, 253-255.

10. Krebs-Smith SM, Smiciklas-Wright H, Guthrie HA et al. (1987) The effects of variety in food choices on dietary quality. J Am Diet Assoc 87, 897-903.

11. McConahy KL, Smiciklas-Wright H, Mitchell DC et al. (2004) Portion size of common foods predicts energy intake among preschool-aged children. J Am Diet Assoc 104, 975-979.

12. Barlow SE \& Expert Committee (2007) Expert committee recommendations regarding the prevention, assessment, and treatment of child and adolescent overweight and obesity: summary report. Pediatrics 120, 164-192.

13. Koletzko B \& Toschke AM (2010) Meal patterns and frequencies: do they affect body weight in children and adolescents? Crit Rev Food Sci Nutr 50, 100-105.

14. Patterson RE, Haines PS \& Popkin BM (1994) Diet quality index: capturing a multidimensional behavior. $J$ Am Diet Assoc 94, 57-64.

15. Batty GD \& Leon DA (2002) Socio-economic position and coronary heart disease risk factors in children and young people. Evidence from UK epidemiological studies. Eur J Public Health 12, 263-272.

16. Fernández-Alvira JM, Mouratidou $\mathrm{T}$, Bammann $\mathrm{K}$ et al. (2013) Parental education and frequency of food consumption in European children: the IDEFICS study. Public Health Nutr 16, 487-498.

17. Brug J, van Stralen MM, te Velde SJ et al. (2012) Differences in weight status and energy-balance related behaviors among schoolchildren across Europe: the ENERGY-project. PLoS One 7, E34742.

18. Szajewska H \& Ruszczynski M (2010) Systematic review demonstrating that breakfast consumption influences body weight outcomes in children and adolescents in Europe. Crit Rev Food Sci Nutr 50, 113-119.

19. Martin HP (1973) Nutrition: its relationship to children's physical, mental, and emotional development. Am J Clin Nutr 26, 766-775.

20. Manios Y, Androutsos O, Katsarou C et al. (2014) Designing and implementing a kindergarten-based, family-involved intervention to prevent obesity in early childhood: the ToyBox-study. Obes Rev 15, 5-13.
21. Manios Y, Grammatikaki E, Androutsos O et al. (2012) A systematic approach for the development of a kindergarten-based intervention for the prevention of obesity in preschool age children: the ToyBox-study. Obes Rev 13, 3-12.

22. Huybrechts I, De Backer G, De Bacquer D et al. (2009) Relative validity and reproducibility of a food-frequency questionnaire for estimating food intakes among Flemish preschoolers. Int J Environ Res Public Health 6, 382-399.

23. Vanhauwaert E (2012) De actieve voedingsdriehoek. Leuven: Acco.

24. European Food Information Council (2009) Food-based dietary guidelines in Europe. http://www.eufic.org/article/ en/expid/food-based-dietary-guidelines-in-europe/ (accessed April 2015).

25. Winkleby MA, Jatulis DE, Frank E et al. (1992) Socioeconomic status and health: how education, income, and occupation contribute to risk factors for cardiovascular disease. Am J Public Health 82, 816-820.

26. De Miguel-Etayo P, Mesana MI, Cardon G et al. (2014) Reliability of anthropometric measurements in European preschool children: the ToyBox-study. Obes Rev 15, 67-73.

27. Cole TJ \& Lobstein T (2012) Extended international (IOTF) body mass index cut-offs for thinness, overweight and obesity. Pediatr Obes 7, 284-294.

28. Mouratidou T, Miguel ML, Androutsos O et al. (2014) Tools, harmonization and standardization procedures of the impact and outcome evaluation indices obtained during a kindergarten-based, family-involved intervention to prevent obesity in early childhood: the ToyBox-study. Obes Rev $\mathbf{1 5}$, 53-60.

29. Vereecken CA, Keukelier E \& Maes L (2004) Influence of mother's educational level on food parenting practices and food habits of young children. Appetite 45, 93-103.

30. O'Malley AS, Kerner JF \& Johnson L (1999) Are we getting the message out to all? Health information sources and ethnicity. Am J Prev Med 17, 198-202.

31. Kant AK \& Graubard BI (2013) Family income and education were related with 30-year time trends in dietary and meal behaviors of American children and adolescents. J Nutr 143, 690-700.

32. Tooze JA, Subar AF, Thompson FE et al. (2004) Psychosocial predictors of energy underreporting in a large doubly labeled water study. Am J Clin Nutr 79, 795-804.

33. González-Gil EM, Mouratidou T, Cardon G et al. (2014) Reliability of primary caregivers reports on lifestyle behaviours of European pre-school children: the ToyBox-study. Obes Rev 15, 61-66.

34. De Coen V, Vansteelandt S, Maes L et al. (2012) Parental socioeconomic status and soft drink consumption of the child. The mediating proportion of parenting practices. Appetite 59, 76-80.

35. Williams SK \& Kelly FD (2005) Relationships among involvement, attachment, and behavioral problems in adolescence: examining father's influence. $J$ Early Adolesc 25, 168-196.

36. De Coen V, De Bourdeaudhuij I, Verbestel V et al. (2014) Risk factors for childhood overweight: a 30-month longitudinal study of 3- to 6-year-old children. Public Health Nutr 17, 1993-2000.

37. Moreno LA, De Henauw S, González-Gross M et al. (2008) Design and implementation of the Healthy Lifestyle in Europe by Nutrition in Adolescence Cross-Sectional Study. Int J Obes (Lond) 32, 5-11.

38. van Stralen MM, te Velde SJ, Singh AS et al. (2011) EuropeaN Energy balance Research to prevent excessive weight Gain among Youth (ENERGY) project: design and methodology of the ENERGY cross-sectional survey. BMC Public Health 11, 65. 